Meta

Journal des tradlucteurs

Translators' Journal

\title{
Appareils et procédés
}

\section{Philippe Desjardins}

Volume 20, numéro 2, juin 1975

URI : https://id.erudit.org/iderudit/002556ar

DOI : https://doi.org/10.7202/002556ar

Aller au sommaire du numéro

Éditeur(s)

Les Presses de l'Université de Montréal

\section{ISSN}

0026-0452 (imprimé)

1492-1421 (numérique)

Découvrir la revue

Citer cet article

Desjardins, P. (1975). Appareils et procédés. Meta, 20(2), 158-158.

https://doi.org/10.7202/002556ar d'utilisation que vous pouvez consulter en ligne.

https://apropos.erudit.org/fr/usagers/politique-dutilisation/ 


\section{APPAREILS ET PROCÉDÉS}

Le Pluri Dictionnaire Larousse (1975) donne les définitions suivantes des mots ALCOOTEST et MAGNÉTOSCOPE :

1. ALCOOTEST - Appareil portatif permettant d'évaluer instantanément l'ivresse d'un sujet par la mesure de la teneur en alcool de l'air expiré.

2. MAGNÉTOSCOPE - Procédé d'enregistrement des images de télévision sur une bande recouverte d'une substance magnétique, et qui permet une rediffusion immédiate des images.

Pour sa part, le Supplément (1970) du Grand Robert donne des mêmes termes les définitions suivantes, plus justes :

1. ALCOOLTEST - Épreuve permettant d'estimer la présence d'alcool dans l'air expiré par une personne, et par conséquent la probabilité d'une intoxication alcoolique.

2. MAGNÉTOSCOPE - Appareil permettant l'enregistrement des images de télévision en même temps que du son (sous forme de signaux de télévision) sur bande magnétique.

Tout le monde sait, ainsi que le dit le Robert, que l'ALCOOTEST est un procédé, tandis que le MAGNÉTOSCOPE est un appareil, et non le contraire.

On voit que le Larousse, malgré plus de cent ans d'expérience dans la confection des dictionnaires, s'est fourvoyé et confond appareil et procédé.

La maison Larousse aura beau invoquer, pour ALCOOTEST, qu'il s'agit là d'un appareil appelé ainsi sur le marché français, il reste qu'à ce titre le mot ne devrait pas figurer parmi les noms communs, ou du moins qu'il aurait fallu indiquer qu'il s'agit d'une marque déposée. D'autre part, comme nom propre, le terme n'entre pas dans le français universel puisqu'il n'y a pas au Canada français d'appareil appelé Alcootest, et n'a pas plus droit de cité dans un dictionnaire que le mot Bic qui est pourtant fort répandu en France comme terme générique pour désigner un stylo à bille. 